\title{
Article \\ Calcifediol Treatment and Hospital Mortality Due to COVID-19: A Cohort Study
}

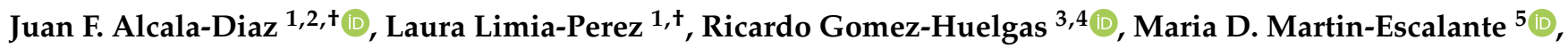 \\ Begoña Cortes-Rodriguez ${ }^{6}$, Jose L. Zambrana-Garcia ${ }^{7}$, Marta Entrenas-Castillo ${ }^{8}$, Ana I. Perez-Caballero ${ }^{1,2}$, \\ Maria D. López-Carmona ${ }^{3,4}$ (D), Javier Garcia-Alegria ${ }^{5,9}$, Aquiles Lozano Rodríguez-Mancheño ${ }^{6}$, \\ Maria del Sol Arenas-de Larriva ${ }^{8}$, Luis M. Pérez-Belmonte ${ }^{3,4} \mathbb{D}^{\mathbb{D}}$, Irwin Jungreis ${ }^{10,11}{ }^{\mathbb{D}}$, Roger Bouillon ${ }^{12}$, \\ Jose Manual Quesada-Gomez ${ }^{13, \ddagger}$ and Jose Lopez-Miranda ${ }^{1,2, *, \ddagger}$
}

check for updates

Citation: Alcala-Diaz, J.F.

Limia-Perez, L.; Gomez-Huelgas, R.; Martin-Escalante, M.D.;

Cortes-Rodriguez, B.;

Zambrana-Garcia, J.L.;

Entrenas-Castillo, M.;

Perez-Caballero, A.I.;

López-Carmona, M.D.;

Garcia-Alegria, J.; et al. Calcifediol Treatment and Hospital Mortality Due to COVID-19: A Cohort Study. Nutrients 2021, 13, 1760. https:// doi.org/10.3390/nu13061760

Academic Editor: Jean Bousquet

Received: 21 April 2021

Accepted: 14 May 2021

Published: 21 May 2021

Publisher's Note: MDPI stays neutral with regard to jurisdictional claims in published maps and institutional affiliations.

Copyright: (C) 2021 by the authors Licensee MDPI, Basel, Switzerland. This article is an open access article distributed under the terms and conditions of the Creative Commons Attribution (CC BY) license (https:/ / creativecommons.org/licenses/by/ $4.0 /)$.
1 Internal Medicine Department, IMIBIC/Reina Sofia University Hospital/University of Córdoba, Avda. Menéndez Pidal s/n, 14004 Córdoba, Spain; juanf.alcala.sspa@juntadeandalucia.es (J.F.A.-D.); laura_limia@hotmail.com (L.L.-P.); anabelperezcaballero@gmail.com (A.I.P.-C.)

2 CIBER Fisiopatologia Obesidad y Nutrición (CIBEROBN), Instituto de Salud Carlos III, 28029 Madrid, Spain

3 Internal Medicine Department, Regional University Hospital of Málaga, Avenida de Carlos Haya, s/n, 29010 Málaga, Spain; ricardogomezhuelgas@hotmail.com (R.G.-H.); mdlcorreo@gmail.com (M.D.L.-C.); luismiguelpb1984@gmail.com (L.M.P.-B.)

4 Biomedical Research Institute of Málaga (IBIMA), University of Málaga (UMA), Avenida de Carlos Haya, s/n, 29010 Málaga, Spain

5 Internal Medicine Department, Hospital Costa del Sol, Agencia Sanitaria Costa del Sol, 29603 Marbella, Málaga, Spain; mmartinescalante@gmail.com (M.D.M.-E.); jalegria@hcs.es (J.G.-A.)

6 Internal Medicine Department, Alto Guadalquivir Hospital, Andújar, 23740 Jaén, Spain; begocortesrod@gmail.com (B.C.-R.); aqlozanorod@gmail.com (A.L.R.-M.)

7 Internal Medicine Department, Hospital de Montilla, Agencia Sanitaria Alto Guadalquivir, 14550 Córdoba, Spain; jlzambrana@ephag.es

8 Pneumology Department, Reina Sofia University Hopital. Avda, Menendez Pidal s/n, 14004 Córdoba, Spain; marenca@gmail.com (M.E.-C.); arlam23@hotmail.com (M.d.S.A.-d.L.)

9 Department of Medicine, University of Málaga (UMA), Red de Investigación en Servicios de Salud en Enfermedades Crónicas (REDISSEC), 29071 Málaga, Spain

10 MIT Computer Science and Artificial Intelligence Laboratory, Cambridge, MA 02139, USA; ILJungr@csail.mit.edu

11 Broad Institute of MIT and Harvard, Cambridge, MA 02142, USA

12 Laboratory of Clinical and Experimental Endocrinology, Department of Chronic Diseases, Metabolism and Ageing, KU Leuven, Herestraat, ON 1/902, 3000 Leuven, Belgium; roger.bouillon@kuleuven.be

13 IMIBIC. CIBER de Fragilidad y Envejecimiento Saludable, Hospital Universitario Reina Sofía, Universidad de Córdoba, Fundación Progreso y Salud, Avda. Menéndez Pidal s/n, 14004 Córdoba, Spain; md1qugoj@uco.es

* Correspondence: md1lomij@uco.es; Tel.: +34-957-010-947; Fax: +34-957-218-250

+ Both authors contributed equally to the work as co-first authors.

$\ddagger$ Both authors contributed equally to the work as co-senior authors.

Abstract: Context. Calcifediol has been proposed as a potential treatment for COVID-19 patients. Objective: To compare the administration or not of oral calcifediol on mortality risk of patients hospitalized because of COVID-19. Design: Retrospective, multicenter, open, non-randomized cohort study. Settings: Hospitalized care. Patients: Patients with laboratory-confirmed COVID-19 between 5 February and 5 May 2020 in five hospitals in the South of Spain. Intervention: Patients received calcifediol (25-hydroxyvitamin $\left.\mathrm{D}_{3}\right)$ treatment $(0.266 \mathrm{mg}$ /capsule, 2 capsules on entry and then one capsule on day $3,7,14,21$, and 28) or not. Main Outcome Measure: In-hospital mortality during the first 30 days after admission. Results: A total of 537 patients were hospitalized with COVID-19 (317 males (59\%), median age, 70 years), and 79 (14.7\%) received calcifediol treatment. Overall, in-hospital mortality during the first 30 days was $17.5 \%$. The OR of death for patients receiving calcifediol (mortality rate of $5 \%$ ) was 0.22 (95\% CI, 0.08 to 0.61 ) compared to patients not receiving such treatment (mortality rate of $20 \% ; p<0.01$ ). Patients who received calcifediol after admission were more likely than those not receiving treatment to have comorbidity and a lower rate of CURB-65 score for pneumonia severity $\geq 3$ (one point for each of confusion, urea $>7 \mathrm{mmol} / \mathrm{L}$, respiratory rate $\geq 30 / \mathrm{min}$, systolic blood pressure $<90 \mathrm{~mm} \mathrm{Hg}$ or diastolic blood pressure $\leq 60 \mathrm{~mm} \mathrm{Hg}$, and age 
$\geq 65$ years), acute respiratory distress syndrome (moderate or severe), c-reactive protein, chronic kidney disease, and blood urea nitrogen. In a multivariable logistic regression model, adjusting for confounders, there were significant differences in mortality for patients receiving calcifediol compared with patients not receiving it $(\mathrm{OR}=0.16$ (95\% CI 0.03 to 0.80$)$. Conclusion: Among patients hospitalized with COVID-19, treatment with calcifediol, compared with those not receiving calcifediol, was significantly associated with lower in-hospital mortality during the first 30 days. The observational design and sample size may limit the interpretation of these findings.

Keywords: COVID-19; calcifediol; SARS-CoV-2; COVID-19 drug treatment; vitamin D

\section{Introduction}

One of the most critical challenges facing contemporary medicine and public health systems in the world has emerged from the 2019 coronavirus (COVID-19) pandemic [1]. The severity of a SARS-CoV-2 infection can range from asymptomatic or mild respiratory symptoms to the development of respiratory failure, multiorgan failure, and death [2]. On 31 January 2020, the World Health Organization (WHO) announced that COVID-19 was labelled a Public Health Emergency of International Importance (PHEIC), and by 18 April 2021, it had affected over 141,334,774 confirmed cases with 3,024,317 deaths reported globally [3]. However, there are still many unclear issues related to transmission, infection, and treatment [1]. Since the beginning of the pandemic, intense pressure has been put on clinicians and researchers to provide advanced treatments to save lives. However, the pathophysiology of severe COVID-19 is very complex. It is a potentially lethal combination of immunopathogenic and immunoprotective responses in a prothrombotic environment [4]. Unfortunately, no single mechanism or pathway discovered so far explains the entire pathophysiology. The problem is that there were only a few successful therapies available, and still fewer have demonstrated efficacy compared to no treatment in clinical trials [1]. It has and still is challenging to treat patients with coronavirus 2019 (COVID-19). Specialists face distressing emergencies in the intensive care unit where, at the start of the pandemic, almost $20 \%$ of the hospitalized patients (with COVID-19) developed Acute Respiratory Distress Syndrome (ARDS) and, despite recent advances in mechanical ventilation and supporting treatment methods, about $65 \%$ of patients with ARDS died [5], explaining why $25 \%$ of critically ill patients with severe COVID-19 died in the first outbreak of the pandemic [6].

At the beginning of the pandemic, in the absence of specific COVID-19-causal treatments clearly effective on mortality, several approved or investigational drugs with in vitro activity against SARS-CoV-2 replication, including antiviral drugs such as lopinavirritonavir, remdesivir, hydroxychloroquine, anti-parasitic ivermectin, and different immunomodulatory medications, were proposed as potentially useful [7]. However, the WHO [8] has generated a strong recommendation against the use of hydroxychloroquine/chloroquine or lopinavir/ritonavir for treatment of COVID-19 of any severity, restricting the use of ivermectin only to clinical trials. For remdesivir, effective in reducing recovery time in adults hospitalized with COVID-19 [9], the WHO has established a conditional recommendation against administering remdesivir in addition to usual care; however, for dexamethasone or other corticosteroids, which are the only therapies that have been shown to reduce mortality so far in patients with severe disease requiring mechanical ventilation of high-flow oxygen [10], the WHO maintains a strong recommendation for the use of systemic corticosteroids for severe or critically ill COVID-19 patients, with a conditional recommendation against their use in patients with mild/moderate COVID-19. Recently, the FDA has approved by Emergency Use Authorization baricitinib in combination with remdesivir in patients requiring invasive mechanical ventilation or extracorporeal membrane oxygenation [11] as well as the neutralizing antibody bamlanivimab (LY-CoV555) [12]. 
Moreover, due to the absence of a specific treatment for ARDS, its management consists of general supportive care required for all critically ill hospitalized patients (prevention of blood clots, infection control, early nutritional assistance, and stress ulcer prophylaxis) as well as the use of ventilation and oxygen therapy $[13,14]$. In this respect, it has been suggested that the vitamin D endocrine system (VDES), by its extra-skeletal actions especially on the lung and the immune system, is a facilitator of immunocompetence with respect to both innate and adaptive immunity [13,15-18].

In this context, the stimulation of the vitamin D receptor (VDR) of the VDES has been proposed to reduce acute respiratory distress syndrome (ARDS), cardiac and coagulopathy risk, and possibly death rates in patients with COVID-19 [15-17,19,20]. Supported by this rationale, some clinical trials and studies of various types are currently underway to test the possible benefit of using oral cholecalciferol (vitamin D3) or calcifediol (also known as 25-hydroxyvitamin $\mathrm{D}_{3}$ ) on patients with COVID-19 [17].

Cholecalciferol (or vitamin D3), obtained through cutaneous synthesis under UV-B light and in small amounts from the diet, is the threshold nutrient of the vitamin D endocrine system (VDES). Transported by vitamin D-binding protein (DBP), it is converted to 25-hydroxyvitamin $\mathrm{D}_{3}$ (25OHD) or calcifediol in the liver, primarily through the action of 25 hydroxylase. Levels of $25 \mathrm{OHD}$ are used by health authorities and scientific societies in America and Europe to establish the status of normality, the definition of vitamin $\mathrm{D}$ deficiency, and the degrees of insufficiency of the same, upon which to establish dietary reference intake values for vitamin D as well as the control of vitamin D deficiency, insufficiency, or excess in the population [21].

Calcifediol is a prohormone of VDES that serves as a substrate for the synthesis of 1,25(OH)2D or calcitriol via 1-hydroxylase (CYP2721B) in the kidney and multiple body cells. Calcitriol functions as a hormone and binds at nuclear level to the vitamin D receptor (VDR) with high affinity, controlling the expression of many genes with a wide range of functional activities [13].

By its relative potency and pharmacokinetic characteristics, when compared to cholecalciferol, oral calcifediol causes a faster increase in 25OHD serum levels [22,23].

The aim of our study was to compare the administration of oral calcifediol in conjunction with best available therapy versus best available therapy only and clinical outcomes among hospital in-patients diagnosed with COVID-19.

\section{Materials and Methods}

Calcifediol was approved by the Ethics Committee for the treatment of COVID19 in the Reina Sofía University Hospital, Córdoba, Spain (EU) (Act-29/2020). Physicians formally informed patients or legal representatives about the calcifediol treatment and recorded their consent in the hospital's electronic medical record. The retrospective data collection and analysis of the patients included in this study were approved by the Málaga provincial research ethics committee (protocol code "Registro-SEMI-COVID-19", 27 March 2020).

\subsection{Study Design, Sites, and Participants}

This retrospective, multicenter cohort study included 537 patients with a clinical picture of acute respiratory infection by COVID-19, radiographic signs of viral pneumonia, and positive SARS-CoV-2 polymerase chain reaction, admitted between 5 February and 5 May 2020 in 5 public health system hospitals in the South of Spain in the regions of Córdoba, Málaga, and Jaén (Hospital Universitario Reina Sofia, Córdoba; Hospital Universitario Regional, Málaga; Hospital Costa del Sol, Marbella; Hospital de Montilla; and Hospital Alto Guadalquivir, Andújar). The study included all sequentially hospitalized patients excluding 76 subjects already reported as part of the randomized pilot study previously reported of COVID-19 patients conducted in Hospital Universitario Reina Sofia [20]. The pharmacy and ethics committee authorized this hospital to use calcifediol treatment (as applied in the pilot trial) at the specialist's discretion. No standardized criteria were used to 
indicate the use of calcifediol treatment. The different healthcare professionals involved in the treatment of the patients described in this study, composed of multidisciplinary teams, indicated at their discretion and under their clinical reasoning the use of the different therapeutic options used to address the infection. In the other hospitals, it was not included as it was not authorized by their respective committees. Medical records were analyzed for medications, pre-existing diseases, clinical measures on admission, outcomes, and adverse effects. Flow-chart of the study is shown in Figure 1.

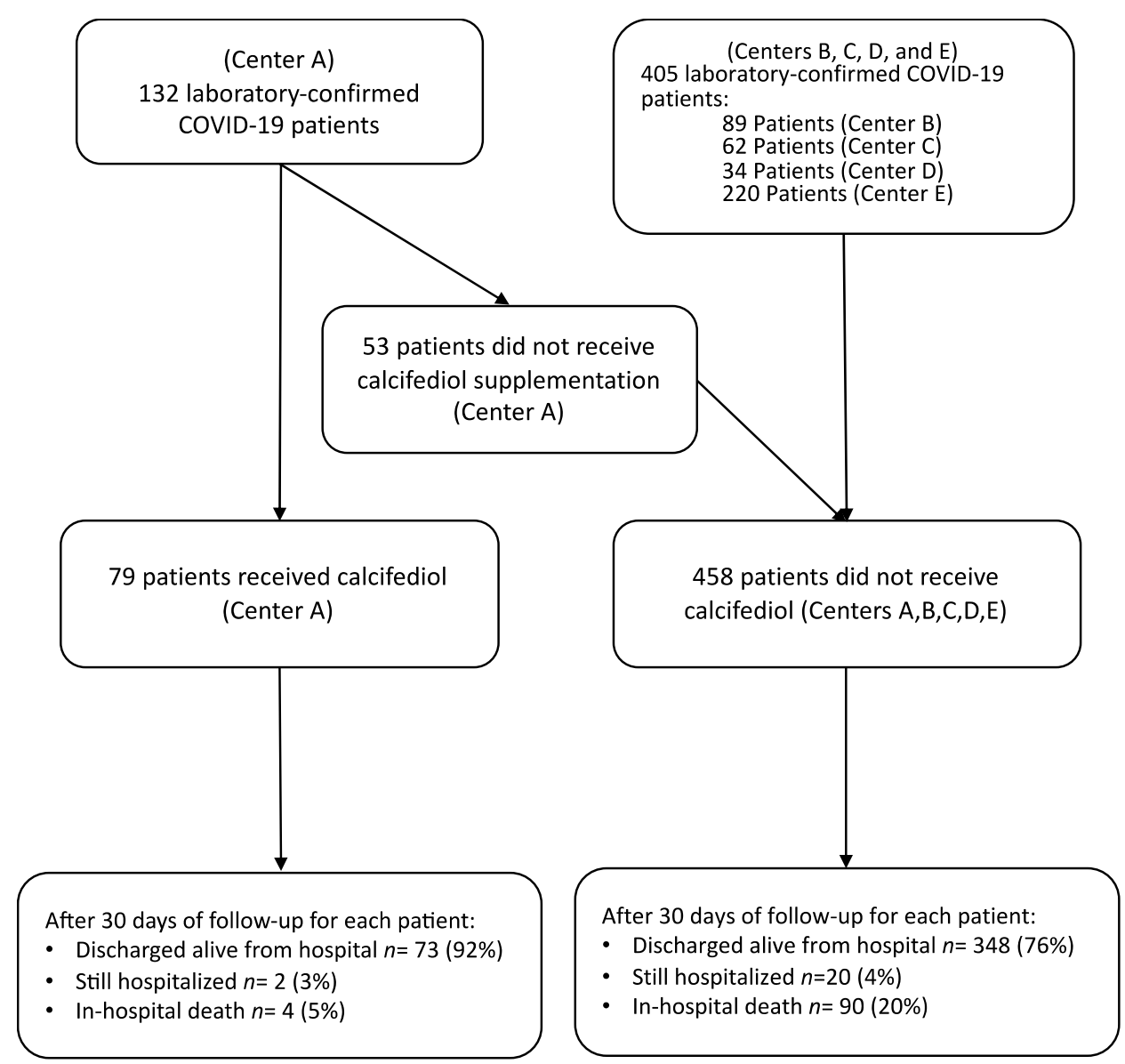

Figure 1. Flow chart of patients included in the study. Center A, Hospital Universitario Reina Sofia (Córdoba, Spain); Center B, Hospital Costa del Sol (Marbella, Spain); Center C, Hospital Alto Gualdalquivir (Andújar, Spain); Center D, Hospital Montilla (Córdoba, Spain); Center E, Hospital Universitario Regional (Málaga, Spain).

\subsection{Laboratory Analysis and Respiratory Function Test}

Clinical specimens required for SARS-CoV-2 diagnostic procedures were obtained on admission by nasopharyngeal exudate sampling following WHO guidelines and recommendations. RNA extraction and real-time RT-PCR (rtRT-PCR) were performed at the local Central Microbiology Laboratory (Code 202 MagCore ${ }^{\circledR}$ Viral Nucleic Acid Extraction Kit by Kapa Biosystems Inc. (Wilmington, MA, USA), Allplex ${ }^{\mathrm{TM}}$ 2019-nCoV Assay by Seegene Inc. (Seoul, Korea), or VIASURE SARS-CoV-2 real-time PCR Detection Kit by CerTest Biotec S.L. (Zaragoza, Spain)).

After blood sample collection, we determined a complete blood count using flow cytometry (ADVIA 2120i, Siemens Healthineers, Erlangen, Germany), coagulation study including d-dimer (coagulation and immunoturbidimetric assay on ACL TOP 700, Instrumentation Laboratory/Werfen), and others parameters related to renal and liver function, lactate dehydrogenase (spectrophotometric assay on Advia chemistry 2400 XPT, Siemens Healthineers, Erlangen, Germany), ferritin, C-reactive protein (CRP) (immunoturbidimetric 
assay on Advia chemistry 2400 XPT, Siemens Healthineers, Erlangen, Germany), and IL-6 (chemiluminescent immunoassay on Advia Centaur XPT, Siemens Healthineers, Erlangen, Germany). $\mathrm{O} 2$ saturation $(\mathrm{SaO} 2)$ and chest radiography were determined in all patients on admission. An expert team of thoracic radiologists evaluated all radiographic evidence. The Berlin definition was used to define ARDS [24]. The CURB-65 score for severity of pneumonia (CURB-65) was calculated according to its international definition [25].

\subsection{Procedures}

According to hospital protocol, all hospitalized patients received the best available treatment for SARS-CoV-2 infection and standard care for pre-existing comorbidities. In addition, patients from the Hospital Universitario Reina Sofia $(n=132)$ were categorized into 2 treatment groups based on having received from admission: (1) oral calcifediol (25-hydroxyvitamin $\left.\mathrm{D}_{3}\right)$ in soft gelatin capsules $(0.532 \mathrm{mg})$, then oral calcifediol $(0.266 \mathrm{mg})$ on day 3 and 7, and then weekly until discharge or ICU admission following the posology of the pilot study from Hospital Universitario Reina Sofia, Córdoba [20] or (2) no treatment with calcifediol. All patients or legal representatives gave their informed consent before initiating treatment with calcifediol, according to the protocol approved by the Pharmacy Committee and by the Ethics Committee for the Treatment of COVID-19 of the Hospital Universitario Reina Sofía, Córdoba, Spain. Patients from the other four centers did not receive treatment with calcifediol, and they were included in the analysis as not-treated patients.

\subsection{Outcome}

We measured the rate of in-hospital deaths in the first 30 days after admission as the primary outcome. Our hypothesis in this retrospective study was that treatment with calcifediol would reduce the risk of death.

\subsection{Statistical Analysis}

To assess the association between treatment groups and clinical variables measured, $\chi 2$ test or Fisher's exact test were used for categorical variables and Student's $t$-test or Kruskal-Wallis test for continuous ones. By multivariable logistic regressions, we calculated the odds ratio of mortality risk by group of treatment, also adjusting by several potential confounders (date of hospitalization before or after approval of calcifediol treatment in Center A, age, gender, center, diabetes, chronic lung disease, smoking status, hypertension, coronary artery disease, cerebrovascular disease, congestive heart failure, $\mathrm{O}_{2}$ saturation at admission, chronic kidney disease, chronic liver disease, dementia, cancer, use of angiotensin-converting enzyme inhibitor (ACEi) or angiotensin II receptor antagonists (ARBs), ratio neutrophil/lymphocytes, blood urea nitrogen, use of systemic corticosteroids during hospitalization, and CURB-65 $\geq 3$ and rate or ARDS moderate or severe as a markers of severity of the disease at admission). A multivariable logistic regression model also including antimicrobial, immunomodulatory, and anticoagulant therapies used during the hospitalization period of patients were calculated. Analyses were completed in IBM $^{\circledR}$ SPSS $^{\circledR}$ Statistics for Macintosh version 20 (Release 20.0.0, Armonk, NY, USA). We considered statistically significant results $p$-values $<0.05$, and all tests were one-sided.

\section{Results}

A total of 537 patients with COVID-19 were admitted in five hospitals in the regions of Córdoba, Málaga, and Jaén in the south of Spain between 14 February and 5 May 2020 and were included in the analysis. Of these patients, 79 (14.7\%) received calcifediol treatment, and $458(85.3 \%)$ did not (Figure 1).

The characteristics of patients at admission according to the group of treatment are shown in Table 1. The non-calcifediol-treated group included more patients with chronic kidney disease and without significant differences in age, gender, smoking status, diabetes, hypertension, cerebrovascular disease, chronic obstructive lung disease, cancer, heart 
failure, coronary artery disease, or dementia. However, the supplemented groups had a higher ratio of any comorbidity than the non-supplemented group. Non-supplemented patients had lower rate of $\mathrm{O}_{2}$ saturation at admission ( $93 \pm 6$ vs. $95 \pm 4$ ), higher levels of CRP, higher blood urea nitrogen, and higher rates of CURB65 $\geq 3$ and ARDS (moderate or severe) at admission without significative differences in neutrophil-to-lymphocyte ratio, $\mathrm{LDH}$, D-dimer, ferritin, or rate of systemic corticosteroids use. The rate of ARDS (moderate or severe) at baseline in the untreated groups was $25 \%$ vs. $10 \%$ in patients that were treated with calcifediol, and no statistical differences were found in the rate of orotracheal intubation during hospitalization (6 vs. 4, $p=0.4)$. Only four patients developed disseminated intravascular coagulation (DIC), with all of them in the untreated group. Other medications dispensed are summarized in Table S1.

Table 1. Baseline characteristics of patients treated or not with calcifediol, days of hospitalization, and mortality after 30 days of follow-up.

\begin{tabular}{|c|c|c|c|}
\hline & Not Treated $(n=458)$ & Treated $(n=79)$ & $p$-Value \\
\hline Age & $67 \pm 16$ & $69 \pm 15$ & 0.23 \\
\hline Male (\%) & 60 & 53 & 0.15 \\
\hline Current smokers (\%) ${ }^{\mathrm{e}}$ & 5 & 3 & 0.26 \\
\hline CURB-65 $\geq 3(\%)$ & 21 & 8 & $<0.01$ \\
\hline ARDS moderate or severe (\%) & 25 & 10 & $<0.01$ \\
\hline Any comorbidity (\%) & 68 & 87 & $<0.01$ \\
\hline Diabetes $(\%)$ & 20 & 20 & 0.5 \\
\hline Hypertension (\%) & 56 & 58 & 0.4 \\
\hline Cerebrovascular disease (\%) & 7 & 6 & 0.53 \\
\hline COPD $(\%)$ & 8 & 3 & 0.06 \\
\hline Heart failure (\%) & 9 & 5 & 0.16 \\
\hline Chronic kidney disease (\%) & 8 & 1 & 0.02 \\
\hline Cancer $(\%)$ & 5 & 4 & 0.23 \\
\hline Coronary heart disease (\%) & 12 & 9 & 0.29 \\
\hline Dementia (\%) & 8 & 8 & 0.60 \\
\hline ACEi/ARBs (\%) & 48 & 39 & 0.13 \\
\hline $\mathrm{SaO} 2$ at admission & $93 \pm 6$ & $95 \pm 4$ & 0.03 \\
\hline $\mathrm{CRP}^{\mathrm{a}}$ & $130 \pm 100$ & $100 \pm 80$ & 0.04 \\
\hline Lymphocytes & $1150 \pm 820$ & $970 \pm 480$ & 0.05 \\
\hline Neutrophil-to-lymphocyte ratio & $7 \pm 7$ & $6 \pm 5$ & 0.66 \\
\hline $\mathrm{LDH}^{\mathrm{b}}$ & $340 \pm 170$ & $330 \pm 150$ & 0.50 \\
\hline D-dimer ${ }^{c}$ & $2500 \pm 7200$ & $1900 \pm 5000$ & 0.48 \\
\hline Ferritin d & $950 \pm 1210$ & $650 \pm 680$ & 0.07 \\
\hline Blood urea nitrogen & $22 \pm 19$ & $16 \pm 15$ & 0.01 \\
\hline Systemic corticosteroids (\%) & 45 & 38 & 0.15 \\
\hline Orotracheal intubation, $n(\%)$ & $26(6)$ & $3(4)$ & 0.36 \\
\hline Mortality, $n(\%)$ & $90(20)$ & $4(5)$ & $<0.001$ \\
\hline
\end{tabular}

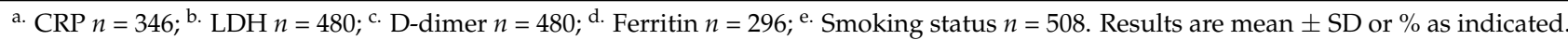
$p$-values were calculated with Fisher's exact test for categorical variables (Exact Sig. 1-sided) and the Student's t-test or Kruskal-Wallis test for continuous ones. Abbreviations: ACEi/ARBs, angiotensin-converting enzyme inhibitor or angiotensin II receptor antagonists; ARDS, acute respiratory distress syndrome; COPD, chronic obstructive pulmonary disease; CRP, c-reactive protein; CURB-65, CURB-65 score for pneumonia severity; $\mathrm{LDH}$, lactate dehydrogenase; $\mathrm{SaO} 2$, arterial oxygen saturation.

Baseline characteristics of patients according to center of recruitment are presented in Supplementary Table S2.

\section{Primary Outcome}

Overall, in-hospital mortality during the first 30 days was $17.5 \%$. Cumulative distribution of in-hospital death according to treatment group is shown in Figure 2. Patients supplemented with calcifediol had lower risk of death during hospitalization ( $5 \%$ vs. $20 \%$, $p$-value $<0.01)$. 


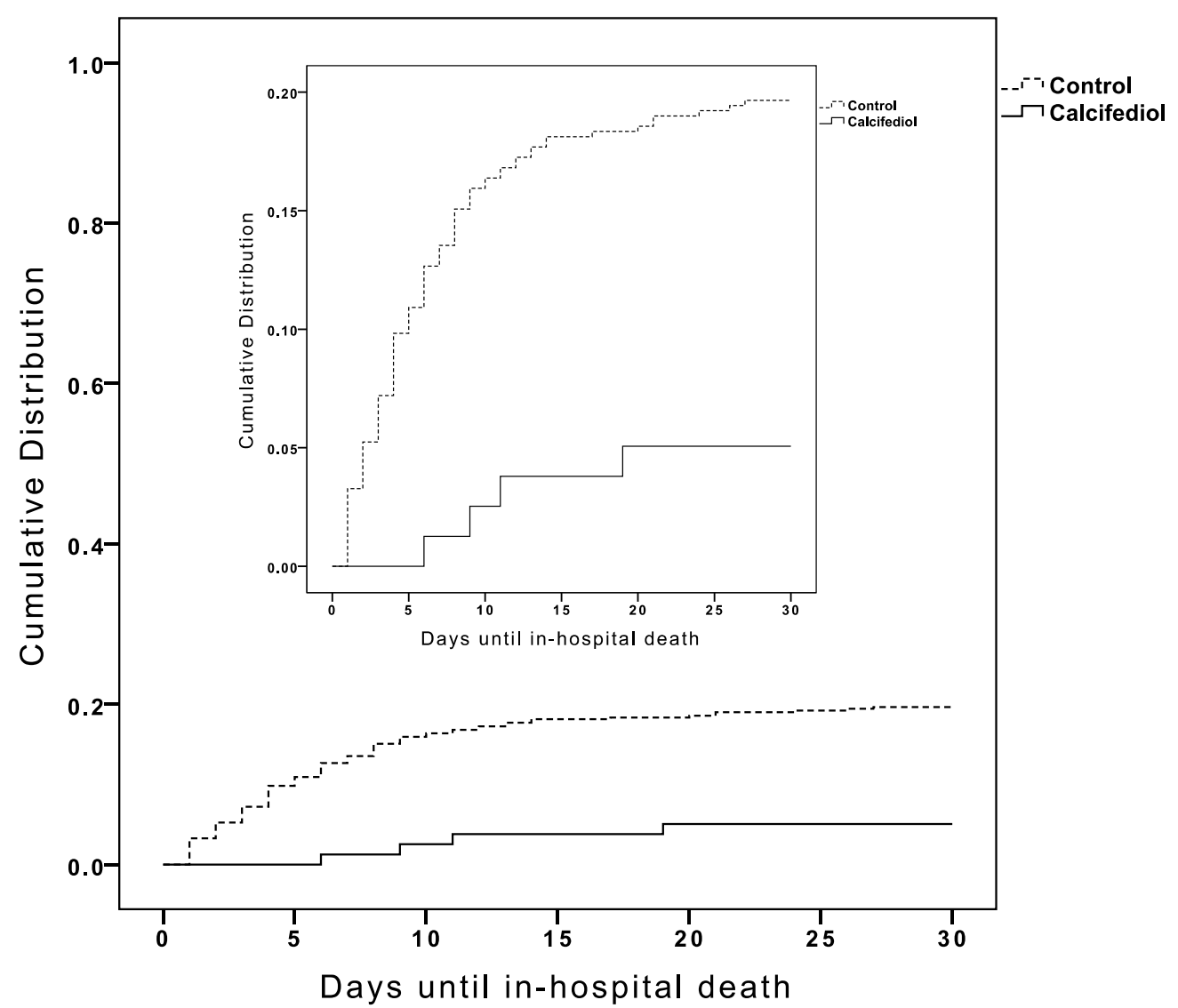

Figure 2. Cumulative distribution of patients presenting in-hospital death according to treatment groups.

The OR of death for patients receiving calcifediol was 0.22 (95\% CI, 0.08-0.61), $p$-value $<0.01$, compared to patients not receiving supplementation.

In multivariate analysis, including potential confounders into the logistic regression model, calcifediol treatment remained statistically significant $(\mathrm{OR}=0.16,95 \% \mathrm{CI}=0.03-0.80)$ with age, center, CURB-65 $\geq 3$, ARDS (moderate or severe) at admission, neutrophil/lymphocytes ratio, prior history of cerebrovascular disease, chronic obstructive pulmonary disease, and cancer as other independent predictors of mortality (Table 2).

The multivariable logistic model developed also included in analyses antimicrobial, immunomodulatory, and anticoagulant therapies used during the hospitalization period of patients, and OR of death for patients treated with calcifediol was 0.2 (95\% CI, 0.04-0.9, $p$-value $=0.04$ ) compared to patients not receiving that treatment.

The number of patients who died among the 53 control patients in center $\mathrm{A}$ and their distribution of confounders versus patients treated with calcifediol are showed in Supplementary Table S3. The statistically significant variables of multivariable logistic regression model for risk of in-hospital death in Center A were calcifediol treatment $(\mathrm{OR}=0.01,95 \% \mathrm{CI}=0.001-0.5)$ and ratio $\mathrm{NL}(\mathrm{OR}=1.6,95 \% \mathrm{CI}=1.1-2.3)$ (Supplementary Table S4).

Even after selecting those patients over 65 years of age and with oxygen saturation levels at admission $<96 \%$, treatment with calcifediol was associated with a lower risk of mortality (OR 0.06, 95\%CI = 0.04-0.8) (Supplementary Table S5). 
Table 2. Statistically significant variables of multivariable logistic regression model for risk of in-hospital death.

\begin{tabular}{|c|c|c|c|}
\hline & OR & $95 \% \mathrm{CI}$ & $p$-Value \\
\hline Calcifediol treatment & 0.16 & $0.03-0.80$ & 0.02 \\
\hline Age & 1.05 & $1.01-1.09$ & 0.008 \\
\hline ARDS (moderate or severe) & 44 & 17-115 & $<0.001$ \\
\hline CURB-65 $\geq 3$ & 2.8 & $1.20-6.7$ & 0.01 \\
\hline Cerebrovascular disease & 3.5 & $1.03-11.6$ & 0.045 \\
\hline COPD & 9.2 & $2.5-34$ & 0.01 \\
\hline Cancer & 5.2 & $1.81-15$ & 0.002 \\
\hline Ratio N/L & 1.06 & $1.00-1.12$ & 0.047 \\
\hline \multicolumn{4}{|l|}{ Center } \\
\hline Center A & 1 (Ref.) & 1 (Ref.) & \\
\hline Center B & 0.25 & $0.06-1.01$ & 0.052 \\
\hline Center C & 0.26 & $0.06-1.10$ & 0.07 \\
\hline Center D & 0.70 & $0.01-0.46$ & 0.006 \\
\hline Center E & 0.31 & $0.09-0.99$ & 0.048 \\
\hline
\end{tabular}

Odd ratios (OR) and $95 \%$ confidence intervals $(95 \% \mathrm{CI})$ have been calculated with multivariable logistic regression adjusted for date of hospitalization before or after approval of calcifediol treatment in Center A, age, gender, center, diabetes, chronic lung disease, smoking status, hypertension, coronary artery disease, cerebrovascular disease, congestive heart failure, $\mathrm{O}_{2}$ saturation at admission, chronic kidney disease, chronic liver disease, dementia, cancer, use of angiotensin-converting enzyme inhibitor (ACEi) or angiotensin II receptor antagonists (ARBs), ratio neutrophil/lymphocytes, blood urea nitrogen, use of systemic corticosteroids during hospitalization, CURB-65 $\geq 3$, ARDS moderate or severe, and use of calcifediol. Abbreviations: ARDS, acute respiratory distress syndrome; COPD, chronic obstructive lung disease; CURB-65, CURB-65 score for pneumonia severity; Ratio N/L, ratio neutrophil/lymphocytes; Center A, Hospital Universitario Reina Sofia (Córdoba, Spain); Center B, Hospital Costa del Sol (Marbella, Spain); Center C, Hospital Alto Gualdalquivir (Andújar, Spain); Center D, Hospital Montilla (Córdoba, Spain); Center E, Hospital Universitario Regional (Málaga, Spain).

\section{Discussion}

In this multicenter observational study of 537 COVID-19 patients, those who received calcifediol had a lower mortality rate during the first 30 days of hospitalization compared to patients not receiving this treatment.

This was a retrospective, observational, non-randomized study, and therefore it is no surprise that the two groups had different baseline characteristics. The treated group had a higher overall risk of comorbidity, whereas the non-supplemented group had lower values of $\mathrm{O}_{2}$ saturation at admission, higher CURB-65 score and higher rate of ARDS moderate or severe, higher levels of inflammatory markers such as CRP, and a higher frequency of kidney failure. Also, in the center where the treatment under study was administered, untreated patients were older, had worse prognostic markers, a higher percentage of comorbidities, dementia, or severity at the time of admission compared to those who received treatment under clinical criteria. However, the protective effect of calcifediol remained significant after adjustment for multiple confounder factors related to severity disease even after selecting those subjects who were older ( $\geq 65$ years) and had worse oxygen saturation levels at admission $(<96 \%)$.

Previously, our group reported in a pilot study of 76 consecutive patients hospitalized with COVID-19 infection that treatment with calcifediol decreased the need for ICU treatment or respiratory assistance [20]. In the present study, we report a lower in-hospital mortality rate during the first 30 days of hospitalization without statistical differences in the use of orotracheal intubation. This last fact could be related to the lack of normalized criteria for ICU admission between hospitals.

In terms of mechanisms, the modulatory ability of the vitamin D endocrine system in host responses to SARS-CoV-2 has been previously identified in the literature, in both the viremic and hyperinflammatory stages of COVID-19 infection [15-17]. Based on many models, there is a clear argument that the VDES/VDR-signaling system can defend against ARDS/acute lung damage by reducing cytokine and chemokine storm and protecting the integrity of the pulmonary epithelial barrier [26-30]. Cells of the immune system and cuboidal-alveolar epithelial coating cells type II (AECII) have the potential to produce 
1,25(OH)2D3 or calcitriol from calcifediol (25OHD3) [13]. Thus, this synthesized calcitriol has the ability to modulate the expression of genes involved in the innate immune response, resulting in the production of antimicrobial peptides (such as cathelicidin), defensins (betadefensine-2), and other components involved in pathogen intracellular destruction (such as toll-like receptors co-receptor CD14) [31]. Furthermore, dsRNA increases the regulation of 1-hydroxylase and sequentially synergizes with calcifediol and calcitriol to induce cathelicidin in viral infection models [31]. Calcifediol and calcitriol were equipotent in the in vivo animal model and (in vitro) on AECII cells [28,31] and the immune system [32,33], suggesting that AECII cells and activated macrophages and lymphocytes were able to actively convert calcifediol to calcitriol.

Vitamin D (25OHD) deficiency had been associated with severity and mortality of patients with ARDS from various causes [34-36] and in SARS-CoV-2 infected patients. Observational studies provide evidence that serum concentrations of $25 \mathrm{OHD}$ are inversely correlated with the incidence or severity of COVID-19. Thus, ecological studies have reported inverse correlations between historical mean concentrations of 25OHD levels and the incidence and mortality of COVID-19 in European countries [19,37]. Lower concentrations of circulating 25OHD have also been reported to be associated with an increased COVID-19 risk [38-41] and even with COVID-19 progression and severity [42-45]. Of course, acute illness or inflammation may decrease serum concentrations of $25 \mathrm{OHD}$, thereby influencing the interpretation of such observational data [46].

A recent meta-analysis of observational studies evaluating vitamin $D$ levels in adult and elderly subjects with COVID-19 found a pattern for a link between 25OHD deficiency and COVID-19 health outcomes [47].

Additionally, the risk of severe COVID-19 infection and a 25OHD deficit overlaps with other conditions such as aging, Black or Asian ethnicity, obesity, and poverty [48]. Serum $25 \mathrm{OHD}$ is frequently decreased during acute inflammatory diseases [49], and 25OHD is thought to be a negative acute-phase reactant. Furthermore, to correct 25OHD deficiency in seriously ill patients [50] or COVID-19 [51], higher than usual doses of cholecalciferol are needed. For this reason, we used calcifediol as a treatment in hospitalized, severe COVID patients. Calcifediol may have some advantages over cholecalciferol [52,53]. It has a near-100 percent intestinal absorption rate and can quickly restore serum 25OHD concentrations since it does not require hepatic 25-hydroxylation. This fact is crucial in clinical circumstances where rapid restoration of serum 25OHD is desired but CYP2R1 expression is hampered, as it may be with COVID. CYP2R1 activity has been shown to be impaired in several animal models [54] and has also been confirmed in COPD and asthma patients [55].

The use of vitamin D3 in boluses administered during hospitalization for COVID-19 has not been shown to reduce the risk of death in studies carried out in Brazil (200,000 $\mathrm{IU} / 5000 \mu \mathrm{g})$ [56] or in France $(80,000 \mathrm{IU} / 2000 \mu \mathrm{g})$ [57]. However, the results of forthcoming, well-designed RCTs will provide new and additional information on the relevance of vitamin D in COVID-19 [58]. In a small, randomized, placebo-controlled trial from India in 25-hydroxyvitamin D deficient ( $<20 \mathrm{ng} / \mathrm{mL}$ ) COVID-19 patients, $62.5 \%$ of participants treated with 60,000 IU/1500 $\mu \mathrm{g} /$ day of vitamin D3 for 7-14 days became negative for SARS-CoV-2 within 21 days compared to only $20.8 \%$ in the untreated participants [51]. Moreover, regular supplementation with vitamin D3, at least in the elderly, in boluses administered regularly during the year prior to diagnosis has shown a reduction in the risk of death and clinical improvement in elderly patients with COVID-19 [59-61].

Unfortunately, serum levels of 25OHD were not available at baseline or during treatment for the exceptional conditions of the first outbreak of COVID-19 [62,63]. According to previous reports, in late winter and early spring, adults in the Córdoba area are relatively $25 \mathrm{OHD}$ deficient $[64,65]$. It is worth mentioning that deficiency $(25 \mathrm{OHD}<20 \mathrm{ng} / \mathrm{mL})$ in COVID-19 patients recently admitted to our hospitals has been repeatedly confirmed (data not shown here); in addition, in subsequent studies at the Reina Sofia University Hospital 
of Córdoba, we verified increase of serum 25OHD above 30-40 ng/mL from the third day of treatment in COVID-19 patients with the proposed calcifediol dosages.

The facts in the literature and the data in this manuscript appear to support principles related to causality, such as strength of association, consistency, temporality, biological gradient, plausibility, and coherence [66]. Our pilot study was the first experimental verification trial reported [20] that additionally encouraged the present study. These two studies together seem to indicate that Calcifediol treatment can reduce the severity of the disease.

The strengths of this study include a cohort of patients hospitalized for COVID-19 in five hospitals of different levels. However, this study has several limitations. First, this is an observational study conducted on patients admitted during the first wave of patients suffering COVID-19. Given that the administration of the treatment was not randomized, and it was based on the clinical judgment of the professionals who attended these patients, the adjustments described above have been made to try to control the possible effect on final mortality of variables that showed statistical significance at the time of admission. However, possible non-identifiable remaining confounding is possible. Secondly, since the data were obtained from the databases of the electronic medical records, we were only able to include those collected in these records for the present study. Data, such as the date of symptom onset before admission, the patients' body mass index, the presence of other comorbidities, and the rate of development of acute kidney injury, among others, were missing in most patients and could not be included. Finally, the post-discharge follow-up events have not been taken into consideration due to lack of such information.

\section{Conclusions}

In conclusion, in this multicenter observational study, patients hospitalized with COVID-19 and treated with calcifediol had lower in-hospital mortality during the first 30 days compared to those patients not supplemented. The observational design and sample size may limit the interpretation of these findings. Results from large-scale, randomized, controlled trials of calcifediol, which are currently underway, are required for validation of our observations.

Supplementary Materials: The following are available online at https: / www.mdpi.com/article / 10.3390/nu13061760/s1: Supplementary Table S1: Antimicrobial, immunomodulatory, and anticoagulant therapies used during the hospitalization period of patients included in analysis according to treatment $(n=537)$; Supplementary Table S2: Baseline characteristics of patients according to center; Supplementary Table S3: Baseline characteristics of patients treated or not with calcifediol, days of hospitalization, and mortality after 30 days of follow-up in Center A; Supplementary Table S4: Statistically significant variables of multivariable logistic regression model for risk of in-hospital death in Center A; Supplementary Table S5: Sensitivity analysis with statistically significant variables of multivariable logistic regression model for risk of In-Hospital Death in selected patients ( $>65$ years and $\mathrm{O} 2$ saturation $<96 \%$ ).

Author Contributions: Conceptualization, J.M.Q.-G. and J.L.-M.; data curation, J.F.A.-D. and L.L.-P.; formal analysis, J.F.A.-D. and L.L.-P.; investigation, J.F.A.-D., L.L.-P., R.G.-H., M.D.M.-E., B.C.-R., J.L.Z.-G., M.E.-C., A.I.P.-C., M.D.L.-C., J.G.-A., A.L.R.-M., M.d.S.A.-d.L., and L.M.P.-B.; methodology, J.F.A.-D. and L.L.-P.; resources, J.L.-M.; supervision, J.L.-M.; visualization, J.F.A.-D. and L.L.-P.; writing-original draft, J.F.A.-D. and L.L.-P.; writing—review and editing, I.J., R.B., J.M.Q.-G., and J.L.-M. All authors have read and agreed to the published version of the manuscript.

Funding: Financed by public funds through the CLINICAL RESEARCH PROGRAM IN COVID-19 OF ANDALUSIA (COVID-0011-2020), Fundación Progreso y Salud, Consejería de Salud y Familias (Junta de Andalucía).

Institutional Review Board Statement: The study was conducted according to the guidelines of the Declaration of Helsinki and approved by the Málaga provincial research ethics committee (protocol code "Registro-SEMI-COVID-19", 27 March 2020).

Informed Consent Statement: Informed consent was obtained from all subjects involved in the study. 
Data Availability Statement: Some or all datasets generated during and/or analyzed during the current study are not publicly available but are available from the corresponding author on reasonable request.

Conflicts of Interest: JFAD received lecture fees from Bayer, Grunenthal Pharma, Esteve, Ferrer, and Boehringer Ingelheim outside the submitted work. LLP received lecture fees from Gebro Pharma S.A., Boehringer Ingelheim, Pfizer, Mylan, Almirall, SANOFI, and ESTEVE outside the submitted work. IJ, RGH, MDME, BCR, JLZG, MEC, AIPC, MDLC, JGA, ALRM, MDSAL, and LMPB have nothing to declare. RB received lecture fees from Abiogen, Faes Farma, Fresenius, and Proctor and Gamble outside the submitted work. JMQG received lecture fees from FAES Farma (Spain) and Amgen related to vitamin D-these activities in no way influenced the writing of the present manuscript. JLM received lecture fees from AMGEN, SANOFI, FERRER, Laboratorios Dr. Esteve, and Boehringer Ingelheim-Lilly outside the submitted work. The funders had no role in the design of the study; in the collection, analyses, or interpretation of data; in the writing of the manuscript, or in the decision to publish the results.

\section{References}

1. Wiersinga, W.J.; Rhodes, A.; Cheng, A.C.; Peacock, S.J.; Prescott, H.C. Pathophysiology, Transmission, Diagnosis, and Treatment of Coronavirus Disease 2019 (COVID-19): A Review. JAMA 2020, 324, 782-793. [CrossRef] [PubMed]

2. Zhu, N.; Zhang, D.; Wang, W.; Li, X.; Yang, B.; Song, J.; Zhao, X.; Huang, B.; Shi, W.; Lu, R.; et al. A Novel Coronavirus from Patients with Pneumonia in China, 2019. N. Engl. J. Med. 2020, 382, 727-733. [CrossRef] [PubMed]

3. COVID-19 Coronavirus Pandemic. Available online: https://www.worldometers.info/coronavirus/? (accessed on 18 April 2021).

4. Arunachalam, P.S.; Wimmers, F.; Mok, C.K.P.; Perera, R.; Scott, M.; Hagan, T.; Sigal, N.; Feng, Y.; Bristow, L.; Tak-Yin Tsang, O.; et al. Systems biological assessment of immunity to mild versus severe COVID-19 infection in humans. Science 2020, 369, 1210-1220. [CrossRef] [PubMed]

5. Chen, N.; Zhou, M.; Dong, X.; Qu, J.; Gong, F.; Han, Y.; Qiu, Y.; Wang, J.; Liu, Y.; Wei, Y.; et al. Epidemiological and clinical characteristics of 99 cases of 2019 novel coronavirus pneumonia in Wuhan, China: A descriptive study. Lancet 2020, 395, 507-513. [CrossRef]

6. Richardson, S.; Hirsch, J.S.; Narasimhan, M.; Crawford, J.M.; McGinn, T.; Davidson, K.W.; the Northwell COVID-19 Research Consortium; Barnaby, D.P.; Becker, L.B.; Chelico, J.D.; et al. Presenting Characteristics, Comorbidities, and Outcomes Among 5700 Patients Hospitalized With COVID-19 in the New York City Area. JAMA 2020, 323, 2052-2059. [CrossRef]

7. Lamontagne, F.; Agoritsas, T.; Macdonald, H.; Leo, Y.S.; Diaz, J.; Agarwal, A.; Appiah, J.A.; Arabi, Y.; Blumberg, L.; Calfee, C.S.; et al. A living WHO guideline on drugs for covid-19. BMJ 2020, 370, m3379. [CrossRef]

8. Therapeutics and COVID-19: Living Guideline. Available online: https://www.who.int/publications/i/item/WHO-2019-nCoVtherapeutics-2021.1 (accessed on 31 March 2021).

9. Beigel, J.H.; Tomashek, K.M.; Dodd, L.E.; Mehta, A.K.; Zingman, B.S.; Kalil, A.C.; Hohmann, E.; Chu, H.Y.; Luetkemeyer, A.; Kline, S.; et al. Remdesivir for the Treatment of Covid-19-Final Report. N. Engl. J. Med. 2020, 383, 1813-1826. [CrossRef]

10. Group, R.C.; Horby, P.; Lim, W.S.; Emberson, J.R.; Mafham, M.; Bell, J.L.; Linsell, L.; Staplin, N.; Brightling, C.; Ustianowski, A.; et al. Dexamethasone in Hospitalized Patients with Covid-19. N. Engl. J. Med. 2021, 384, 693-704. [CrossRef]

11. Kalil, A.C.; Patterson, T.F.; Mehta, A.K.; Tomashek, K.M.; Wolfe, C.R.; Ghazaryan, V.; Marconi, V.C.; Ruiz-Palacios, G.M.; Hsieh, L.; Kline, S.; et al. Baricitinib plus Remdesivir for Hospitalized Adults with Covid-19. N. Engl. J. Med. 2021, 384, 795-807. [CrossRef]

12. Chen, P.; Nirula, A.; Heller, B.; Gottlieb, R.L.; Boscia, J.; Morris, J.; Huhn, G.; Cardona, J.; Mocherla, B.; Stosor, V.; et al. SARS-CoV-2 Neutralizing Antibody LY-CoV555 in Outpatients with Covid-19. N. Engl. J. Med. 2021, 384, 229-237. [CrossRef]

13. Bouillon, R.; Marcocci, C.; Carmeliet, G.; Bikle, D.; White, J.H.; Dawson-Hughes, B.; Lips, P.; Munns, C.F.; Lazaretti-Castro, M.; Giustina, A.; et al. Skeletal and Extraskeletal Actions of Vitamin D: Current Evidence and Outstanding Questions. Endocr. Rev. 2019, 40, 1109-1151. [CrossRef] [PubMed]

14. Fan, E.; Brodie, D.; Slutsky, A.S. Acute Respiratory Distress Syndrome: Advances in Diagnosis and Treatment. JAMA 2018, 319, 698-710. [CrossRef] [PubMed]

15. Grant, W.B.; Lahore, H.; McDonnell, S.L.; Baggerly, C.A.; French, C.B.; Aliano, J.L.; Bhattoa, H.P. Evidence that Vitamin D Supplementation Could Reduce Risk of Influenza and COVID-19 Infections and Deaths. Nutrients 2020, 12, 988. [CrossRef] [PubMed]

16. Bilezikian, J.P.; Bikle, D.; Hewison, M.; Lazaretti-Castro, M.; Formenti, A.M.; Gupta, A.; Madhavan, M.V.; Nair, N.; Babalyan, V.; Hutchings, N.; et al. MECHANISMS IN ENDOCRINOLOGY: Vitamin D and COVID-19. Eur. J. Endocrinol. 2020, 183, R133-R147. [CrossRef]

17. Quesada-Gomez, J.M.; Entrenas-Castillo, M.; Bouillon, R. Vitamin D receptor stimulation to reduce acute respiratory distress syndrome (ARDS) in patients with coronavirus SARS-CoV-2 infections: Revised Ms SBMB 2020_166. J. Steroid. Biochem. Mol. Biol. 2020, 202, 105719. [CrossRef] [PubMed] 
18. Shah Alam, M.; Czajkowsky, D.M.; Aminul Islam, M.; Ataur Rahman, M. The role of vitamin D in reducing SARS-CoV-2 infection: An update. Int. Immunopharmacol. 2021, 97, 107686. [CrossRef] [PubMed]

19. Ilie, P.C.; Stefanescu, S.; Smith, L. The role of vitamin D in the prevention of coronavirus disease 2019 infection and mortality. Aging Clin. Exp. Res. 2020, 32, 1195-1198. [CrossRef] [PubMed]

20. Entrenas Castillo, M.; Entrenas Costa, L.M.; Vaquero Barrios, J.M.; Alcala Diaz, J.F.; Lopez Miranda, J.; Bouillon, R.; Quesada Gomez, J.M. Effect of calcifediol treatment and best available therapy versus best available therapy on intensive care unit admission and mortality among patients hospitalized for COVID-19: A pilot randomized clinical study. J. Steroid Biochem. Mol. Biol. 2020, 203, 105751. [CrossRef] [PubMed]

21. Giustina, A.; Bouillon, R.; Binkley, N.; Sempos, C.; Adler, R.A.; Bollerslev, J.; Dawson-Hughes, B.; Ebeling, P.R.; Feldman, D.; Heijboer, A.; et al. Controversies in Vitamin D: A Statement from the Third International Conference. JBMR Plus 2020, 4 , e10417. [CrossRef]

22. Jetter, A.; Egli, A.; Dawson-Hughes, B.; Staehelin, H.B.; Stoecklin, E.; Goessl, R.; Henschkowski, J.; Bischoff-Ferrari, H.A. Pharmacokinetics of oral vitamin D(3) and calcifediol. Bone 2014, 59, 14-19. [CrossRef]

23. Barker, T.; May, H.T.; Doty, J.R.; Lappe, D.L.; Knowlton, K.U.; Carlquist, J.; Konery, K.; Inglet, S.; Chisum, B.; Galenko, O.; et al. Vitamin D supplementation protects against reductions in plasma 25-hydroxyvitamin D induced by open-heart surgery: Assess-d trial. Physiol. Rep. 2021, 9, e14747. [CrossRef] [PubMed]

24. Force, A.D.T.; Ranieri, V.M.; Rubenfeld, G.D.; Thompson, B.T.; Ferguson, N.D.; Caldwell, E.; Fan, E.; Camporota, L.; Slutsky, A.S. Acute respiratory distress syndrome: The Berlin Definition. JAMA 2012, 307, 2526-2533. [CrossRef]

25. Lim, W.S.; van der Eerden, M.M.; Laing, R.; Boersma, W.G.; Karalus, N.; Town, G.I.; Lewis, S.A.; Macfarlane, J.T. Defining community acquired pneumonia severity on presentation to hospital: An international derivation and validation study. Thorax 2003, 58, 377-382. [CrossRef] [PubMed]

26. Xiao, D.; Li, X.; Su, X.; Mu, D.; Qu, Y. Could SARS-CoV-2-induced lung injury be attenuated by vitamin D? Int. J. Infect Dis. 2020. [CrossRef] [PubMed]

27. Xu, J.; Yang, J.; Chen, J.; Luo, Q.; Zhang, Q.; Zhang, H. Vitamin D alleviates lipopolysaccharideinduced acute lung injury via regulation of the reninangiotensin system. Mol. Med. Rep. 2017, 16, 7432-7438. [CrossRef]

28. Shi, Y.Y.; Liu, T.J.; Fu, J.H.; Xu, W.; Wu, L.L.; Hou, A.N.; Xue, X.D. Vitamin D/VDR signaling attenuates lipopolysaccharideinduced acute lung injury by maintaining the integrity of the pulmonary epithelial barrier. Mol. Med. Rep. 2016, 13, 1186-1194. [CrossRef]

29. Kong, J.; Zhu, X.; Shi, Y.; Liu, T.; Chen, Y.; Bhan, I.; Zhao, Q.; Thadhani, R.; Li, Y.C. VDR attenuates acute lung injury by blocking Ang-2-Tie-2 pathway and renin-angiotensin system. Mol. Endocrinol. 2013, 27, 2116-2125. [CrossRef]

30. Zheng, S.; Yang, J.; Hu, X.; Li, M.; Wang, Q.; Dancer, R.C.A.; Parekh, D.; Gao-Smith, F.; Thickett, D.R.; Jin, S. Vitamin D attenuates lung injury via stimulating epithelial repair, reducing epithelial cell apoptosis and inhibits TGF-beta induced epithelial to mesenchymal transition. Biochem. Pharmacol. 2020, 177, 113955. [CrossRef]

31. Hansdottir, S.; Monick, M.M.; Hinde, S.L.; Lovan, N.; Look, D.C.; Hunninghake, G.W. Respiratory epithelial cells convert inactive vitamin D to its active form: Potential effects on host defense. J. Immunol. 2008, 181, 7090-7099. [CrossRef]

32. Rafique, A.; Rejnmark, L.; Heickendorff, L.; Moller, H.J. 25(OH)D3 and 1.25(OH)2D3 inhibits TNF-alpha expression in human monocyte derived macrophages. PLoS ONE 2019, 14, e215383. [CrossRef]

33. Andrukhov, O.; Andrukhova, O.; Hulan, U.; Tang, Y.; Bantleon, H.P.; Rausch-Fan, X. Both 25-hydroxyvitamin-D3 and 1,25dihydroxyvitamin-D3 reduces inflammatory response in human periodontal ligament cells. PLoS ONE 2014, 9, e90301. [CrossRef] [PubMed]

34. Dancer, R.C.; Parekh, D.; Lax, S.; D’Souza, V.; Zheng, S.; Bassford, C.R.; Park, D.; Bartis, D.G.; Mahida, R.; Turner, A.M.; et al. Vitamin D deficiency contributes directly to the acute respiratory distress syndrome (ARDS). Thorax 2015, 70, 617-624. [CrossRef] [PubMed]

35. Thickett, D.R.; Moromizato, T.; Litonjua, A.A.; Amrein, K.; Quraishi, S.A.; Lee-Sarwar, K.A.; Mogensen, K.M.; Purtle, S.W.; Gibbons, F.K.; Camargo, C.A., Jr.; et al. Association between prehospital vitamin D status and incident acute respiratory failure in critically ill patients: A retrospective cohort study. BMJ Open Respir. Res. 2015, 2, e000074. [CrossRef]

36. Park, S.; Lee, M.G.; Hong, S.B.; Lim, C.M.; Koh, Y.; Huh, J.W. Effect of vitamin D deficiency in Korean patients with acute respiratory distress syndrome. Korean J. Intern Med. 2018, 33, 1129-1136. [CrossRef] [PubMed]

37. Laird, E.; Rhodes, J.; Kenny, R.A. Vitamin D and Inflammation: Potential Implications for Severity of Covid-19. Ir. Med. J. 2020, 113,81

38. D'Avolio, A.; Avataneo, V.; Manca, A.; Cusato, J.; De Nicolo, A.; Lucchini, R.; Keller, F.; Cantu, M. 25-Hydroxyvitamin D Concentrations Are Lower in Patients with Positive PCR for SARS-CoV-2. Nutrients 2020, 12, 1359. [CrossRef]

39. Meltzer, D.O.; Best, T.J.; Zhang, H.; Vokes, T.; Arora, V.; Solway, J. Association of Vitamin D Status and Other Clinical Characteristics With COVID-19 Test Results. JAMA Netw. Open 2020, 3, e2019722. [CrossRef]

40. Kaufman, H.W.; Niles, J.K.; Kroll, M.H.; Bi, C.; Holick, M.F. SARS-CoV-2 positivity rates associated with circulating 25hydroxyvitamin D levels. PLoS ONE 2020, 15, e0239252. [CrossRef]

41. Hernandez, J.L.; Nan, D.; Fernandez-Ayala, M.; Garcia-Unzueta, M.; Hernandez-Hernandez, M.A.; Lopez-Hoyos, M.; MunozCacho, P.; Olmos, J.M.; Gutierrez-Cuadra, M.; Ruiz-Cubillan, J.J.; et al. Vitamin D Status in Hospitalized Patients with SARS-CoV-2 Infection. J. Clin. Endocrinol. Metab. 2020. [CrossRef] 
42. Maghbooli, Z.; Sahraian, M.A.; Ebrahimi, M.; Pazoki, M.; Kafan, S.; Tabriz, H.M.; Hadadi, A.; Montazeri, M.; Nasiri, M.; Shirvani, A.; et al. Vitamin D sufficiency, a serum 25-hydroxyvitamin D at least $30 \mathrm{ng} / \mathrm{mL}$ reduced risk for adverse clinical outcomes in patients with COVID-19 infection. PLoS ONE 2020, 15, e0239799. [CrossRef]

43. Radujkovic, A.; Hippchen, T.; Tiwari-Heckler, S.; Dreher, S.; Boxberger, M.; Merle, U. Vitamin D Deficiency and Outcome of COVID-19 Patients. Nutrients 2020, 12, 2757. [CrossRef] [PubMed]

44. Merzon, E.; Tworowski, D.; Gorohovski, A.; Vinker, S.; Golan Cohen, A.; Green, I.; Frenkel-Morgenstern, M. Low plasma 25(OH) vitamin D level is associated with increased risk of COVID-19 infection: An Israeli population-based study. FEBS J. 2020, 287, 3693-3702. [CrossRef]

45. Meltzer, D.O.; Best, T.J.; Zhang, H.; Vokes, T.; Arora, V.M.; Solway, J. Association of Vitamin D Levels, Race/Ethnicity, and Clinical Characteristics With COVID-19 Test Results. JAMA Netw. Open 2021, 4, e214117. [CrossRef] [PubMed]

46. Smolders, J.; van den Ouweland, J.; Geven, C.; Pickkers, P.; Kox, M. Letter to the Editor: Vitamin D deficiency in COVID-19: Mixing up cause and consequence. Metabolism Clin. Exp. 2021, 115, 154434. [CrossRef] [PubMed]

47. Pereira, M.; Dantas Damascena, A.; Galvao Azevedo, L.M.; de Almeida Oliveira, T.; da Mota Santana, J. Vitamin D deficiency aggravates COVID-19: Systematic review and meta-analysis. Crit. Rev. Food Sci. Nutr. 2020, 1-9. [CrossRef]

48. Martineau, A.R.; Forouhi, N.G. Vitamin D for COVID-19: A case to answer? Lancet Diabetes Endocrinol. 2020, 8, 735-736. [CrossRef]

49. Waldron, J.L.; Ashby, H.L.; Cornes, M.P.; Bechervaise, J.; Razavi, C.; Thomas, O.L.; Chugh, S.; Deshpande, S.; Ford, C.; Gama, R. Vitamin D: A negative acute phase reactant. J. Clin. Pathol. 2013, 66, 620-622. [CrossRef]

50. Amrein, K.; Sourij, H.; Wagner, G.; Holl, A.; Pieber, T.R.; Smolle, K.H.; Stojakovic, T.; Schnedl, C.; Dobnig, H. Short-term effects of high-dose oral vitamin D3 in critically ill vitamin D deficient patients: A randomized, double-blind, placebo-controlled pilot study. Crit. Care 2011, 15, R104. [CrossRef]

51. Rastogi, A.; Bhansali, A.; Khare, N.; Suri, V.; Yaddanapudi, N.; Sachdeva, N.; Puri, G.D.; Malhotra, P. Short term, high-dose vitamin D supplementation for COVID-19 disease: A randomised, placebo-controlled, study (SHADE study). Postgrad. Med. J. 2020. [CrossRef]

52. Navarro-Valverde, C.; Sosa-Henriquez, M.; Alhambra-Exposito, M.R.; Quesada-Gomez, J.M. Vitamin D3 and calcidiol are not equipotent. J. Steroid Biochem. Mol. Biol. 2016, 164, 205-208. [CrossRef]

53. Quesada-Gomez, J.M.; Bouillon, R. Is calcifediol better than cholecalciferol for vitamin D supplementation? Osteoporos. Int. 2018, 29, 1697-1711. [CrossRef] [PubMed]

54. Bouillon, R.; Bikle, D. Vitamin D Metabolism Revised: Fall of Dogmas. J. Bone Miner. Res. 2019, 34, 1985-1992. [CrossRef]

55. Jolliffe, D.A.; Stefanidis, C.; Wang, Z.; Kermani, N.Z.; Dimitrov, V.; White, J.H.; McDonough, J.E.; Janssens, W.; Pfeffer, P.; Griffiths, C.J.; et al. Vitamin D Metabolism Is Dysregulated in Asthma and Chronic Obstructive Pulmonary Disease. Am. J. Respir. Crit. Care Med. 2020, 202, 371-382. [CrossRef] [PubMed]

56. Murai, I.H.; Fernandes, A.L.; Sales, L.P.; Pinto, A.J.; Goessler, K.F.; Duran, C.S.C.; Silva, C.B.R.; Franco, A.S.; Macedo, M.B.; Dalmolin, H.H.H.; et al. Effect of a Single High Dose of Vitamin D3 on Hospital Length of Stay in Patients with Moderate to Severe COVID-19: A Randomized Clinical Trial. JAMA 2021, 325, 1053-1060. [CrossRef] [PubMed]

57. Annweiler, G.; Corvaisier, M.; Gautier, J.; Dubee, V.; Legrand, E.; Sacco, G.; Annweiler, C. Vitamin D Supplementation Associated to Better Survival in Hospitalized Frail Elderly COVID-19 Patients: The GERIA-COVID Quasi-Experimental Study. Nutrients 2020, 12, 3377. [CrossRef] [PubMed]

58. Annweiler, C.; Mercat, A.; Souberbielle, J.C. Learning from previous methodological pitfalls to propose well-designed trials on vitamin D in COVID-19. J. Steroid Biochem. Mol. Biol. 2021, 211, 105901. [CrossRef]

59. Ling, S.F.; Broad, E.; Murphy, R.; Pappachan, J.M.; Pardesi-Newton, S.; Kong, M.F.; Jude, E.B. High-Dose Cholecalciferol Booster Therapy is Associated with a Reduced Risk of Mortality in Patients with COVID-19: A Cross-Sectional Multi-Centre Observational Study. Nutrients 2020, 12, 3799. [CrossRef]

60. Cangiano, B.; Fatti, L.M.; Danesi, L.; Gazzano, G.; Croci, M.; Vitale, G.; Gilardini, L.; Bonadonna, S.; Chiodini, I.; Caparello, C.F.; et al. Mortality in an Italian nursing home during COVID-19 pandemic: Correlation with gender, age, ADL, vitamin D supplementation, and limitations of the diagnostic tests. Aging 2020, 12, 24522-24534. [CrossRef]

61. Annweiler, C.; Hanotte, B.; Grandin de l'Eprevier, C.; Sabatier, J.M.; Lafaie, L.; Celarier, T. Vitamin D and survival in COVID-19 patients: A quasi-experimental study. J. Steroid Biochem. Mol. Biol. 2020, 204, 105771. [CrossRef]

62. Heaney, R.P. Guidelines for optimizing design and analysis of clinical studies of nutrient effects. Nutr. Rev. 2014, 72, 48-54. [CrossRef]

63. Grant, W.B.; Boucher, B.J.; Bhattoa, H.P.; Lahore, H. Why vitamin D clinical trials should be based on 25-hydroxyvitamin D concentrations. J. Steroid Biochem. Mol. Biol. 2018, 177, 266-269. [CrossRef]

64. Mata-Granados, J.M.; Luque de Castro, M.D.; Quesada Gomez, J.M. Inappropriate serum levels of retinol, alpha-tocopherol, 25 hydroxyvitamin D3 and 24,25 dihydroxyvitamin D3 levels in healthy Spanish adults: Simultaneous assessment by HPLC. Clin. Biochem. 2008, 41, 676-680. [CrossRef]

65. Quesada-Gomez, J.M.; Diaz-Curiel, M.; Sosa-Henriquez, M.; Malouf-Sierra, J.; Nogues-Solan, X.; Gomez-Alonso, C.; RodriguezManas, L.; Neyro-Bilbao, J.L.; Cortes, X.; Delgadillo, J. Low calcium intake and inadequate vitamin D status in postmenopausal osteoporotic women. J. Steroid Biochem. Mol. Biol. 2013, 136, 175-177. [CrossRef]

66. Hill, A.B. The Environment and Disease: Association or Causation? Proc. R. Soc. Med. 1965, 58, 295-300. [CrossRef] 